\title{
Nitrogênio na água do solo do ecossistema Campina Amazônica ${ }^{(1)}$
}

\author{
Antonio dos Santos $\left({ }^{2}\right)$ \\ Maria de Nazaré G. Ribeiro $\left({ }^{2}\right)$
}

\section{Resumo}

As principais fontes de nitrogênio na água do solo do ecossistema Campina Amazônica são: o material em decomposição (litter), chuva, água de lavagem da floresta e produtos do metabolismo de microrganismos. Foram analisadas amostras de água colhidas do lençol freático em quatro locais no solo de areia branca (Regosol), com relação aos compóstos do nitrogênio (amônia, nitritos e nitratos), e calculadas as concentraçōes de nitrogênio orgânico e total. O nitrogênio de origem orgânica apresenta concentração superior às demais fraçōes analisadas; o nitrogênio amoniacal, como principal produto de desdobramento do material orgânico vegetal por microrganismos, aparece em segunda escala de grandeza, enquanto que nitritos e nitratos estão quase sempre ausentes devido às condições ácidas do meio ( $\mathrm{pH} 3,0)$. Existem variações anuais e sazonais dos compostos nitrogenados, aparecendo valores mais elevados no meio do período seco, devido a imobilização do lençol freático. Nos solos de areia branca, em condiçōes naturais, o nitrogênio não é fator limitante para o desenvolvimento da vegetação natural.

\section{INTRODUÇÃo}

A matéria nitrogenada mais complexa, na solução do solo, é formada de proteinas, ligninas e hemicelulose, sem valor direto para a nutrição dos vegetais superiores. Entretanto, estes compostos são aproveitados por microrganismos que vivem no solo e água do lençol freático (água intersticial) dos solos arenosos.

Através do trabalho de transformação enzimática destes compostos, os microrganismos adquirem a energia indispensável ao seu metabolismo e o nitrogênio liberado, dos compostos que sofrem este desdobramento, pode seguir duas direções: ou é sintetizado para compostos celulares dos próprios organismos transformadores ou permanece no solo sob a forma de compostos mais simples, como por exemplo, amônia.

Os compostos nitrogenados no ecossistema, provêm essencialmente dos residuos orgânicos vegetais, pois os solos de areia branca são pobres em compostos nitrogenados de origem inorgânica. A regularidade e quantidade destes dependem, entretanto, da velocidade do desdobramento. Esse nitrogênio incorporado aos restos de vegetais, microrganismos e água do solo, quando da derrubada $\mathrm{e}$ queima da vegetação natural em equilíbrio biológico, retorna rapidamente à atmosfera sob a forma molecular de $\mathrm{N}_{2}$ ou $\mathrm{N}_{2} \mathrm{O}$, tornando estes solos deficientes em compostos nitrogenados (Brinkmann \& Nascimento, 1973).

$\mathrm{Na}$ Amazônia Central, área próxima de Manaus, há uma introdução de compostos nitrogenados pelo "litter" na ordem de 106 $\mathrm{kg} / \mathrm{ha} / \mathrm{ano}$ na mata de terra firme (Klinge \& Rodrigues, 1968). Através das precipitações pluviais esta introdução é da ordem de $10 \mathrm{~kg}$ de N-total; $3,2 \mathrm{~kg}$ de $\mathrm{N}$-amoniacal; $2,5 \mathrm{~kg}$ de $\mathrm{N}$-orgânico e $2,5 \mathrm{~kg}$ de $\mathrm{N}$-nitratos/ha/ano (Anon. 1972 a). Além disso, as condições de elevadas temperaturas e umidade, predominantes no ecossistema em questão (Ribeiro \& Santos, 1975), aceleram o desdobramento de compostos nitrogenados mais complexos.

\section{MATERIAL E MÉTODOS}

No período de março de 1973 a setembro de 1974, excetuando o período seco (setembro de 1973 a fevereiro de 1974), foram analisadas amostras de água do lençol freático em quatro locais do ecossistema Campina Amazônica, com relação aos compostos nitrogenados na solução do solo em uma formação arenosa ao longo da rodovia BR-174 (tre-

\footnotetext{
(1) - Trabalho inteiramente subvencionado pelo Conselho Nacional de Desenvolvimento Científico e Tecnológico (CNPq).

(2) - Instituto Nacional de Pesquisas da Amazônia, Manaus.
} 
cho Manaus-Caracarai) $\mathrm{km} 60$, pertencente ao INPA (Long. $60^{\circ} 00^{\prime} 00^{\prime \prime} \mathrm{W}$ e Lat. $2^{\circ} 30^{\prime} 00^{\prime \prime} \mathrm{S}$ ), denominada Reserva Biológica de Campina (Fig. 1).

As amostras foram colhidas semanalmente de poços instalados em diferentes situações ecológicas. Estes são tubos de polietile-

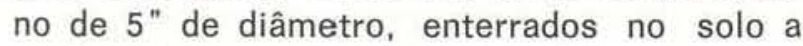
profundidade variáveis $\left(P_{1}-4,8 \mathrm{~m} ; \mathrm{P}_{2}-2,5\right.$ $m ; P_{3}-2,1 m ; P_{4}-1,8 m$ ), tendo a extremidade inferior fechada e suas paredes ranhuradas até uma altura de $1,5 \mathrm{~m}$, permitindo o livre movimento da água dentro do tubo.

A comunidade florestal é referida na literatura como "Campina Forest in the Rio Negro Region" (Takeuchi, 1961). Sua estrutura consiste de árvores em três estratos, quase sempre cobertas de epífitas e lianas. O estrato mais alto da Campina está representado pelo Macucu (Aldina latifolia Benth, Leguminosa) e Casca Doce (Glycoxylon inophyllum, Sapotácea). Os estratos inferiores têm composição florística ainda indefinida.

O solo, do tipo Regosol (IPEAAOC, 1971), caracteriza-se por apresentar um perfil do tipo AC. Aparece com o horizonte orgânico pouco profundo, constituído de u'a camada de húmus de $1-5 \mathrm{~cm}$ sob o Macucu e nas ilhas de mato formadas em sua maior parte de Casca Doce, apresenta acumulação de material parcialmente decomposto de até $30 \mathrm{~cm}$ de espessura.

As raizes das plantas encontram-se limitadas à camada de material em decomposição e raramente alcançam $50 \mathrm{~cm}$ de profundidade (Fig. 2), visto que elas exploram ao máximo a manta orgânica que recobre o solo.

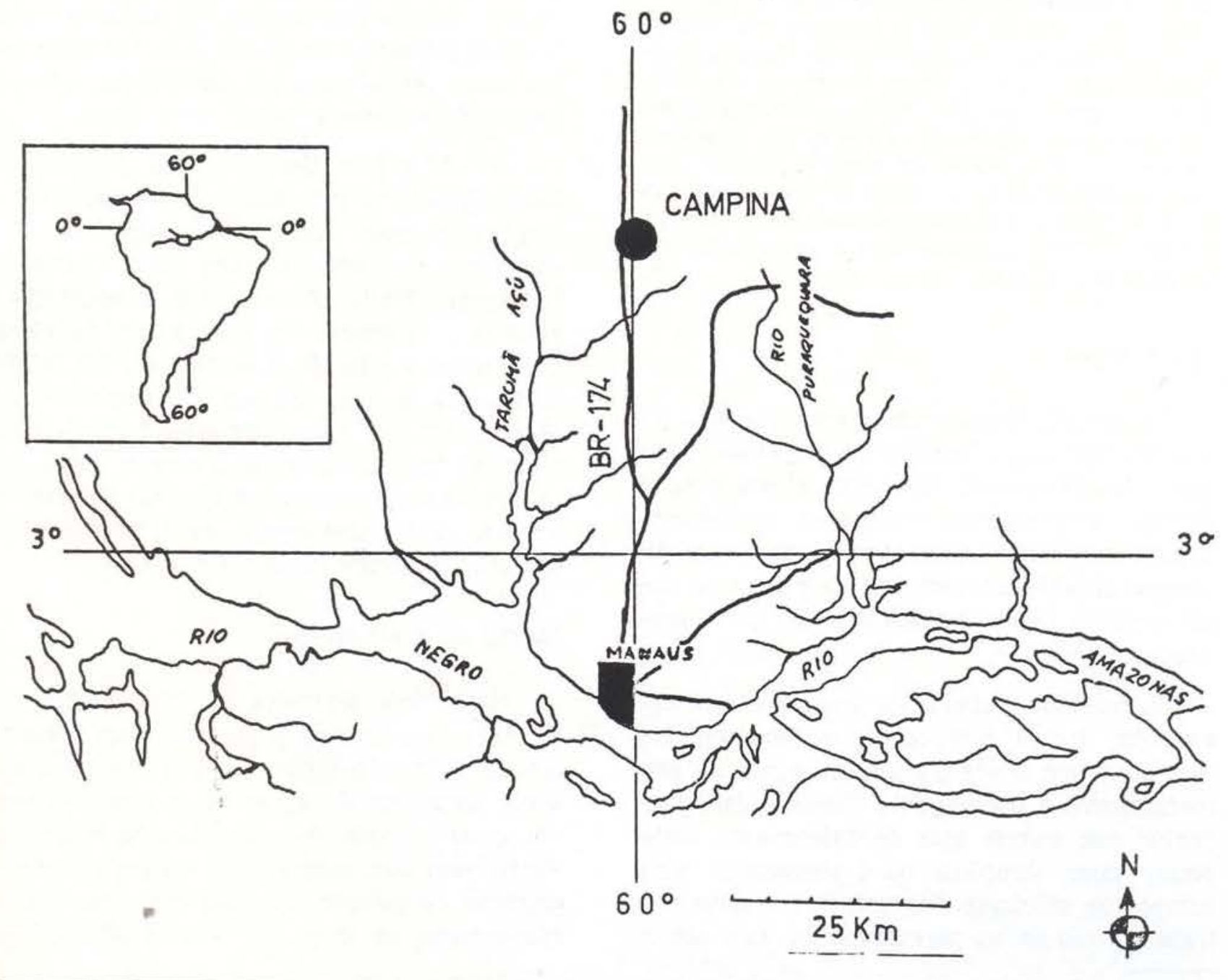

Fig. 1 - Local de trabalho próximo de Manaus. 

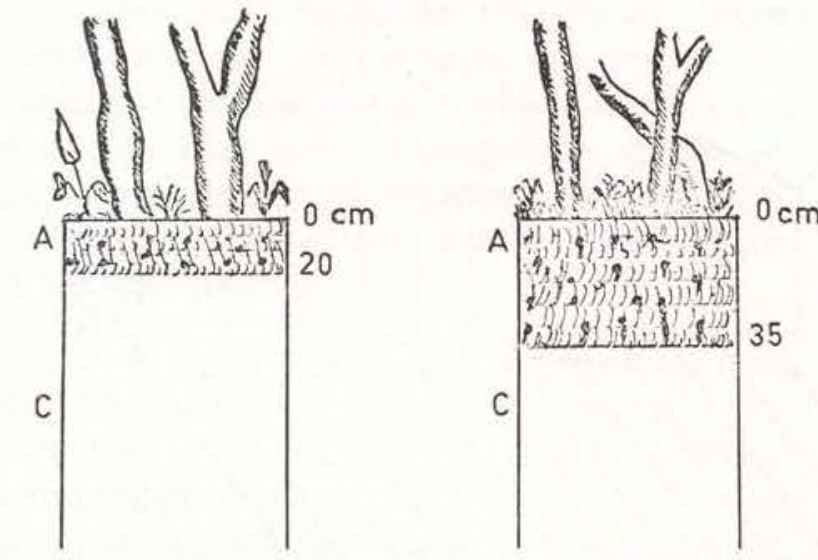

Wig. 2 - Representação esquemática da distribuibuição das raízes no solo da Campina.

Todo o perfil apresenta-se arenoso com estrutura de grãos individuais, solto e muito friável, aparecendo seixos após os 3 metros de profundidade misturados com caolim.

\section{AMOSTRAS E PROCEDIMIENTOS ANALÍTICOS}

1 - Nitrogênio amoniacal: foi determinado por nesslerização direta, sendo que as amostras colhidas no campo foram fixadas com $5 \mathrm{ml}$ de $\mathrm{H}_{2} \mathrm{SO}_{4} 4 \mathrm{~N}$ (IBP, Handbook n.. 8 . 1969) em frascos de polietileno de $1000 \mathrm{ml}$ a fim de eliminar a possibilidade de oxidação.

2 - Nitritos e nitratos: usou-se o processo de (Grasshof, 1964) adaptado para as condições de trabalho na Amazônia Central. As amostras foram tratadas com $\mathrm{CHCl}_{3}$ a fim de minimizar as transformações bacterianas. No laboratório foram submetidas a tratamento com soluções de $\mathrm{NaOH}$ e $\mathrm{ZnSO}_{4}$ a $10 \%$ para eliminar a coloração produzida pelo material orgânico coloidal.

3 - Nitrogênio de Kjeldhal: foi determinado em amostras normais (sem tratamento prévio); no laboratório $1000 \mathrm{ml}$ foram tratados com $3 \mathrm{ml}$ de $\mathrm{H}_{2} \mathrm{SO}_{4}$ concentrado e mistura reativa de Selênio (Reagente Merck n. 8030) sob temperatura controlada até completa oxidação cio material orgânico.

. 4 - Nitrogênio total: foi calculado como a soma das frações $(\mathrm{N}-\mathrm{Kj})+\left(\mathrm{N}-\mathrm{NO}_{2}\right)+\left(\mathrm{N}-\mathrm{NO}_{3}\right)$.

5 - Nitrogênio orgânico: calculado como a diferença entre as frações $(\mathrm{N}-\mathrm{Kj})-\left(\mathrm{N}-\mathrm{NH}_{4}\right)$.

\section{Resultados}

O nitrogênio amoniacal liberado nos solos ácidos como o da Campina $(\mathrm{pH} \mathrm{3,0)}$ é particularmente importante para a nutrição dos vegetais superiores. A concentração de nitrogênio amoniacal na água do lençol freático (Tabela 1 e figura 3) apresenta variações características para cada parte do ecossistema.

TABELA 1

Amônia livre $\mathrm{N}-\mathrm{NH}_{4}(\mathrm{ug} / 1)$ Médias mensais

\begin{tabular}{|c|c|c|c|c|}
\hline \multirow{2}{*}{ Mês } & \multicolumn{4}{|c|}{ C A M P I N A } \\
\hline & $\mathbf{P}_{1}$ & $\mathbf{P}_{2}$ & $\mathbf{P}_{3}$ & $\mathbf{P}_{4}$ \\
\hline III. 1973 & 148 & 211 & 219 & 433 \\
\hline IV & 259 & 312 & 203 & 267 \\
\hline $\mathrm{V}$ & 235 & 334 & 193 & 325 \\
\hline VI & 353 & 512 & 222 & 375 \\
\hline VII & 239 & $2 \tilde{5} 4$ & 161 & 310 \\
\hline VIII & 120 & 198 & 179 & 203 \\
\hline IX & - & 283 & 141 & 236 \\
\hline III. 1974 & 145 & 180 & 116 & 266 \\
\hline IV & 180 & 240 & 92 & 194 \\
\hline $\mathrm{V}$ & 122 & 248 & 123 & 210 \\
\hline VI & 156 & 246 & 123 & 212 \\
\hline VII & 160 & 252 & 152 & 215 \\
\hline VIII & - & 287 & 200 & 212 \\
\hline IX & - & 216 & 138 & 172 \\
\hline Mínima & 78 & $14 \overline{5}$ & 55 & 103 \\
\hline Miáxima & 403 & 655 & 324 & 641 \\
\hline Niédia & 192 & 269 & 162 & 259 \\
\hline
\end{tabular}

No período de março a setembro de 1973 , devido as condiçōes climáticas e a conseqüente mobilização do lençol freático, houve maior variação das concentrações de nitrogênio amoniacal em todos os poços. No período de março a setembro de 1974 , esta variação foi menos acentuada, podendo ser observado que os poços de n. 1 e 3 , por estarem localizados em manchas de areia branca e afastados da zona de deposição dos detritos, apresentam concentrações mais baixas que os de n. 2 e 4 , evidenciando assim o trabalho de desdobramento do material orgânico vegetal por parte de microrganismos. 


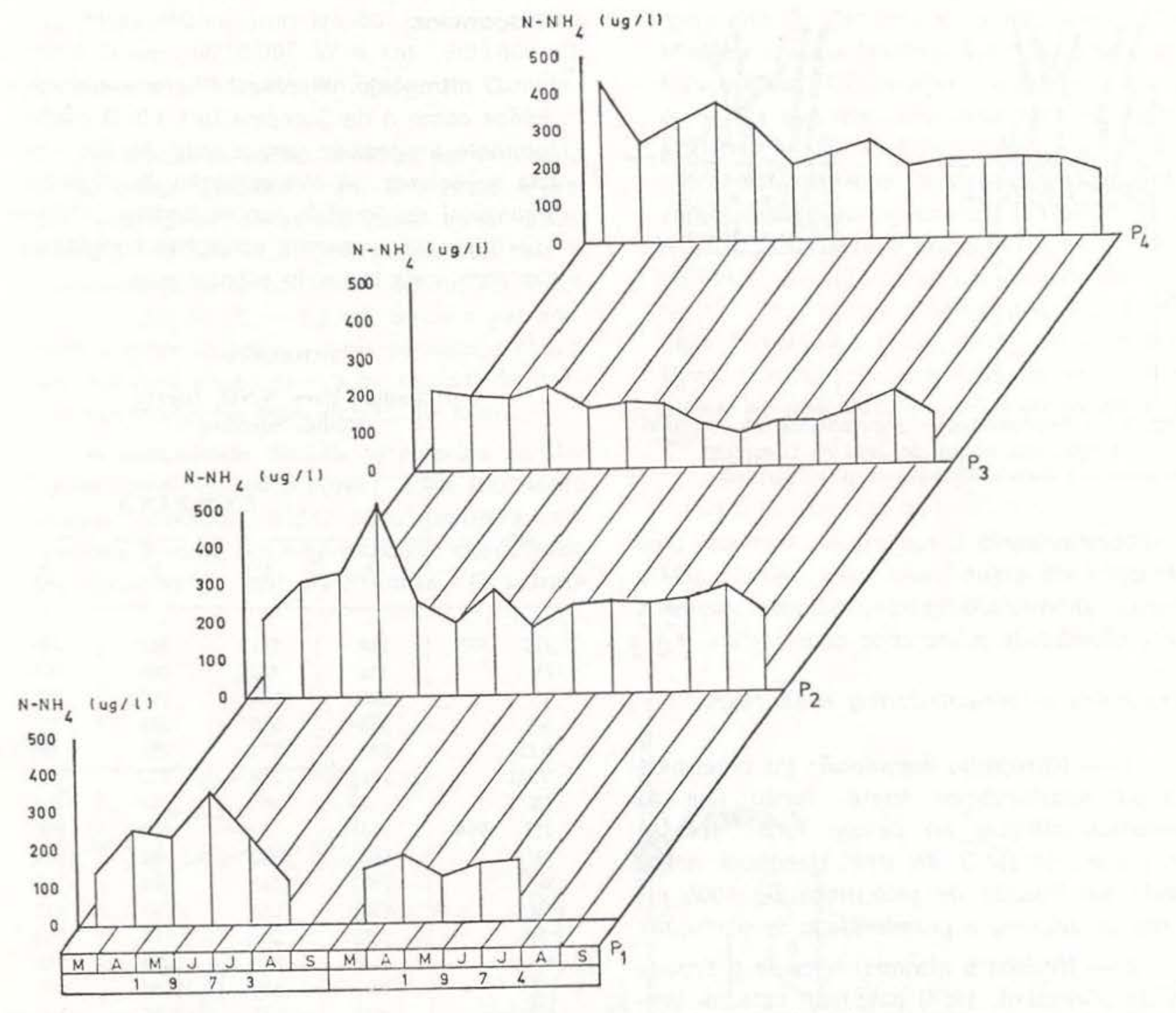

Fig. 3 - Variações mensais de Nitrogênio amoniacal.

Nitritos e nitratos: Nos solos de areia branca o processo de nitrificação fica bastante inibido devido às condições ácidas do meio, e a oxidação amônia-nitritos-nitratos se realiza muito lentamente. Sendo esta troca bastante lenta a concentração de nitritos nas amostras foram sempre nulas (abaixo da sensibilidade do método $1 \mathrm{ug} / \mathrm{I}$ ).

Nas áreas onde estão localizados os poços n. 1 e 3 , não existindo acumulação de material caido "litter", a água do solo em seu movimento ascendente e descendente entra em contato com o ar contido nos espaços porosos do solo arenoso, sendo constantemente oxigenada, permitindo o desenvolvimento de uma flora bacteriana, fungos e actinomicetos que em presença de oxigênio dissolvido na água desdobram o nitrogênio amoniacal, aparecendo nestes locais significativas concentrações de nitratos (Tabela 2 e figura 4), o que não acontece nos poços n. 2 e 4 localizados na zona de acumulação de material vegetal. Aí o oxigênio contido no solo é utilizado para a respiração da fauna existente nos horizontes iniciais do solo e oxidação do material orgânico, tornando-se nestes locais a água do lençol freático pobre em oxigênio dissolvido (Figura 5), não permitindo o desenvolvimento da microflora bacteriana.

Estudos iniciais revelaram a existência de \pm 100000 colônias de bactérias e fungos por $\mathrm{ml}$ de água no poço $\mathrm{n} .^{\circ} 3$ (Brinkmann, inédito). 
Sendo esta forma de nitrogênio a' mais aproveitada para a formação dos corpos orgânicos, as baixas concentrações mostram que a medida com que a oxidação se realiza, nitratos são absorvidos do meio e voltam a integrar o ciclo produtivo da vegetação e do solo no ecossistema.

$\mathrm{O}$ nitrogênio de crigem orgânica na água do solo (Tabela 3 e figura 6), representa o produto final do desdobramento dos compostos nitrogenados incorporados ao material vegetal e restos de microrganismos; o complcxo é formado pelas frações dos ácidos orgânicos (hú- mico, fúlvico, apocrénico), ligninas e hemicelulose, que constituem o colóide do solo. As variações apresentadas são características das situações ecológicas dos poços.

O nitrogênio total representa o somatório das frações orgânicas e inorgânicas na solução do solo. Devido a deficiência de nitritos e nitratos a concentração de $\mathrm{N}$-total é, pràticamente, igual à concentração de N-Kj (Tabelas 4 e 5). Nos solos de areia branca em equilibrio biológico, o nitrogênio não é fator linitante para o desenvolvimento da comunidade florestal (Figuras 7 e 8 ).

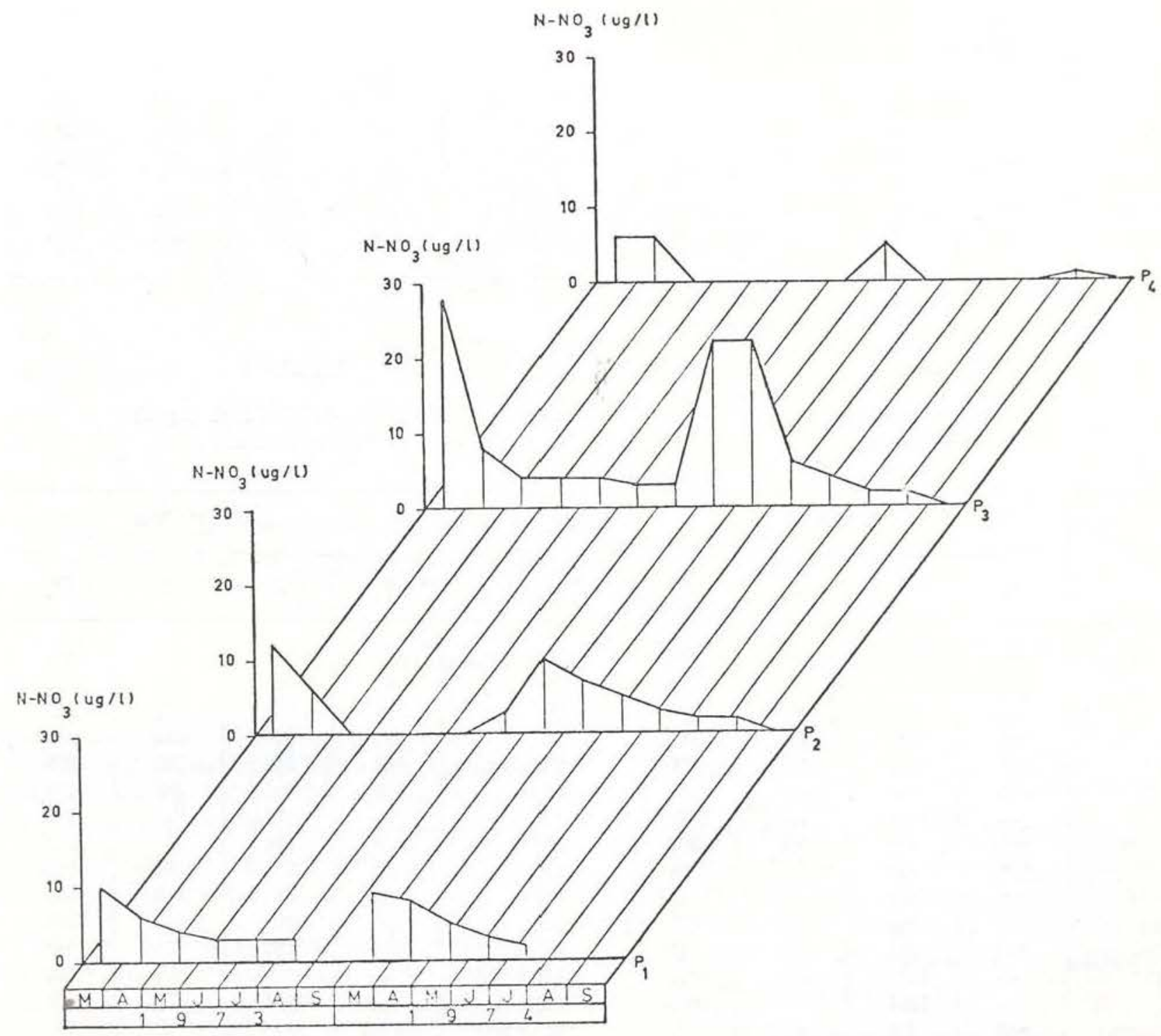

Fig. 4 - Variações mensais de Nitrogênio nítrico. 
TABELA 2

Nitratos $\mathrm{N} \cdot \mathrm{NO}_{3}$ (ug/1)

Médias mensais

\begin{tabular}{|c|c|c|c|c|}
\hline \multirow{2}{*}{ Mês } & \multicolumn{4}{|c|}{ CA M P I N A } \\
\hline & $\mathbf{P}_{1}$ & $\mathbf{P}_{2}$ & $\mathbf{P}_{3}$ & $\mathbf{P}_{4}$ \\
\hline III. 1973 & 10 & 12 & 28 & 6 \\
\hline IV & $\epsilon$ & 6 & 8 & 6 \\
\hline V & 4 & 0 & 4 & 0 \\
\hline VI & 3 & J & 4 & 0 \\
\hline VII & 3 & 0 & 4 & 0 \\
\hline VIII & 3 & 0 & 3 & 0 \\
\hline IX & - & 3 & 3 & c \\
\hline III. 1974 & 9 & 10 & 22 & 5 \\
\hline IV & 8 & 7 & 22 & 0 \\
\hline $\mathrm{V}$ & 5 & 5 & 6 & 0 \\
\hline VI & 3 & 3 & 4 & 0 \\
\hline VII & 2 & 2 & 2 & 0 \\
\hline VIII & - & 2 & 2 & 1 \\
\hline IX & - & 0 & 0 & 0 \\
\hline Mínima & 1 & 1 & 1 & 1 \\
\hline Máxima & 25 & 55 & 60 & 10 \\
\hline Média & 5 & 4 & 8 & 1 \\
\hline
\end{tabular}

TABELA 4

Nitrogênio total (ug/1)

Médias mensais

\begin{tabular}{|c|c|c|c|c|}
\hline \multirow{2}{*}{ Mês } & \multicolumn{4}{|c|}{ C A M P I N A } \\
\hline & $P_{1}$ & $\mathbf{P}_{2}$ & $\mathbf{P}_{3}$ & $\mathbf{P}_{4}$ \\
\hline III. 1973 & 813 & 884 & 865 & 906 \\
\hline IV & 748 & 827 & 564 & 797 \\
\hline V & 621 & 959 & 400 & 828 \\
\hline VI & 654 & 906 & 438 & 841 \\
\hline VII & 797 & 842 & 710 & 730 \\
\hline VIII & 609 & 701 & 662 & 709 \\
\hline IX & - & 1134 & 788 & 1040 \\
\hline III. 1974 & 483 & 624 & 368 & 807 \\
\hline IV & 578 & 896 & 403 & 854 \\
\hline $\mathrm{V}$ & 660 & 956 & 458 & 1000 \\
\hline VI & 640 & 958 & 436 & 928 \\
\hline VII & 757 & 991 & 507 & 945 \\
\hline VIII & - & 1214 & 875 & 1053 \\
\hline IX & $=-$ & 1114 & 875 & 1083 \\
\hline Mínima & 404 & 474 & 292 & 302 \\
\hline Máxima & 997 & 1512 & 1032 & 1633 \\
\hline Média & 669 & 929 & 596 & 894 \\
\hline
\end{tabular}

TABELA 3

Nitrogênio orgânico (ug/1) Médias mensais

\begin{tabular}{|c|c|c|c|c|}
\hline \multirow{2}{*}{ Mês } & \multicolumn{4}{|c|}{ C A M P I N A } \\
\hline & $\mathbf{P}_{1}$ & $\mathbf{P}_{2}$ & $\mathbf{P}_{3}$ & $\mathbf{P}_{4}$ \\
\hline III. 1973 & 655 & 661 & 618 & 473 \\
\hline IV & 484 & 398 & 333 & 524 \\
\hline V & 382 & 625 & 199 & 497 \\
\hline VI & 297 & 394 & 212 & 466 \\
\hline VII & 535 & 588 & 545 & 420 \\
\hline VIII & 486 & 503 & 479 & 506 \\
\hline IX & - & 844 & 644 & 804 \\
\hline III. 1974 & 328 & 314 & 230 & 537 \\
\hline IV & 426 & 649 & 289 & 660 \\
\hline V & 533 & 703 & 330 & 794 \\
\hline VI & 480 & 709 & 309 & 717 \\
\hline VII & 595 & 734 & 353 & 731 \\
\hline VIII & - & 925 & 622 & 840 \\
\hline IX & - & 897 & 737 & 911 \\
\hline Minima & 223 & 270 & 156 & 300 \\
\hline Máxima & 875 & 1319 & 861 & 1524 \\
\hline Média & 473 & 639 & 421 & 634 \\
\hline
\end{tabular}

TABELA 5

Nitrogênio de Kjeldhal (ug/1)

Médias mensais

\begin{tabular}{|c|c|c|c|c|}
\hline \multirow{2}{*}{ Mês } & \multicolumn{4}{|c|}{ CA M P I N A } \\
\hline & $\mathbf{P}_{1}$ & $\mathbf{P}_{2}$ & $\mathbf{P}_{3}$ & $P_{4}$ \\
\hline III. 1973 & 803 & 872 & 837 & 900 \\
\hline IV & 741 & 824 & 536 & 791 \\
\hline V & 617 & 959 & 392 & 822 \\
\hline VI & 651 & 906 & 434 & 841 \\
\hline VII & 794 & 842 & 706 & 730 \\
\hline VIII & 606 & 701 & 658 & 709 \\
\hline IX & - & 1127 & 785 & 1040 \\
\hline III. 1974 & 474 & 494 & 346 & 803 \\
\hline IV & 570 & 889 & 381 & 854 \\
\hline V & 655 & 951 & 452 & 1000 \\
\hline VI & 636 & 955 & 432 & 928 \\
\hline VII & 755 & 989 & 505 & 946 \\
\hline VIII & - & 1211 & 873 & 1052 \\
\hline IX & - & 1114 & 875 & 1083 \\
\hline Mínima & 393 & 458 & 260 & 302 \\
\hline Máxima & 993 & 1510 & 1031 & 1627 \\
\hline Média & 663 & 773 & 593 & 892 \\
\hline
\end{tabular}




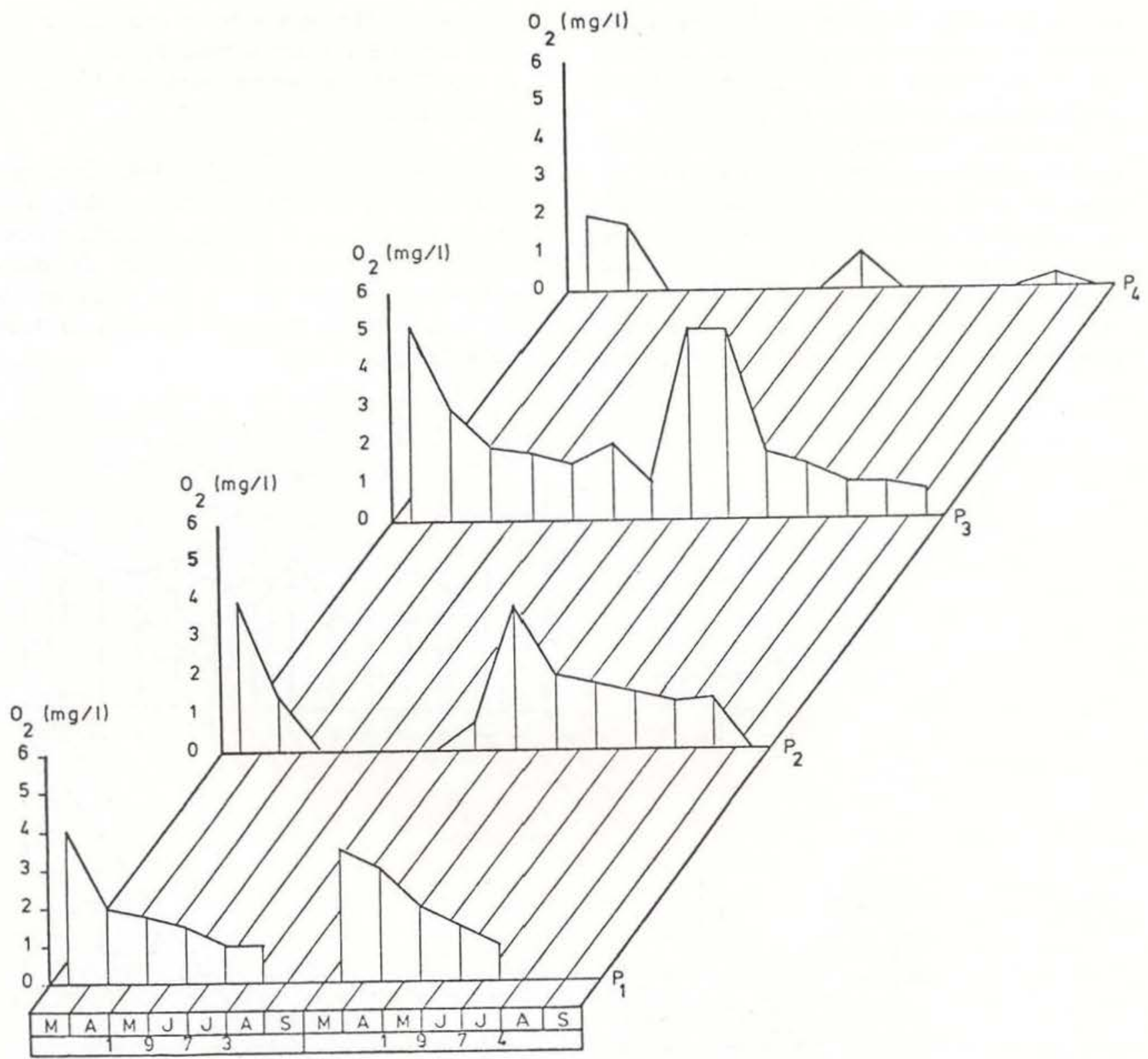

Fig. 5 - Variações mensais de Oxigênio dissolvido.

Os dados analíticos sobre os compostos nitrogenados na solução do solo da Campina estão superiores às demais concentrações encontradas para as águas pretas da Amazônia Central (Anon, 1972 b).

Estas investigações serão intensificadas no decorrer dos próximos anos com o estudo das fraçōes orgânicas existentes na água do solo, material vegetal, solo e atmosfera da floresta, nos estudos integrados do ciclo do nitrogênio na Amazônia Central.

\section{CONCLUSÕES}

As principais fontes de nitrogênio na água do solo do ecossistema Campina Amazônica são: o material em decomposição (litter), água da chuva, água de lavagem da floresta, fixação por leguminosas e subprodutos do metabolismo de microrganismos.

As fases do nitrogênio na solução do soio não são exclusivas nem se desenvolvem em caráter contínuo; existe apenas predominân- 
cia do nitrogênio orgânico, em face da rápida velocidade de percolação, devido à constituição física arenosa do solo e das condições climáticas que prevalecem no ecossistema.

O ecossistema tem uma tendência natural para perder nitrogênio em excesso da solução do solo, isto porque a área está sujeita a um mecanismo de lixiviação e drenagem intensos e os mecanismos de decomposição atuam com suas ações super-rápidas.

O ecossistema desenvolveu formas especiais para manter uma provisão de nitrogênio suficiente a fim de manter o equilíbrio biológico, a existência deste mecanismo é a grande quantidade de leguminosas nas faixas de areia branca.

Trabalhos integrados de silvicultura, química do solo, agricultura e meio ambiente, a fim de conservar o nitrogênio, poderão ter resultados espetaculares em termos de aproveitamento racional năo só dos solos arenosos, mas de todos os grupos de solos na Amazônia Central.

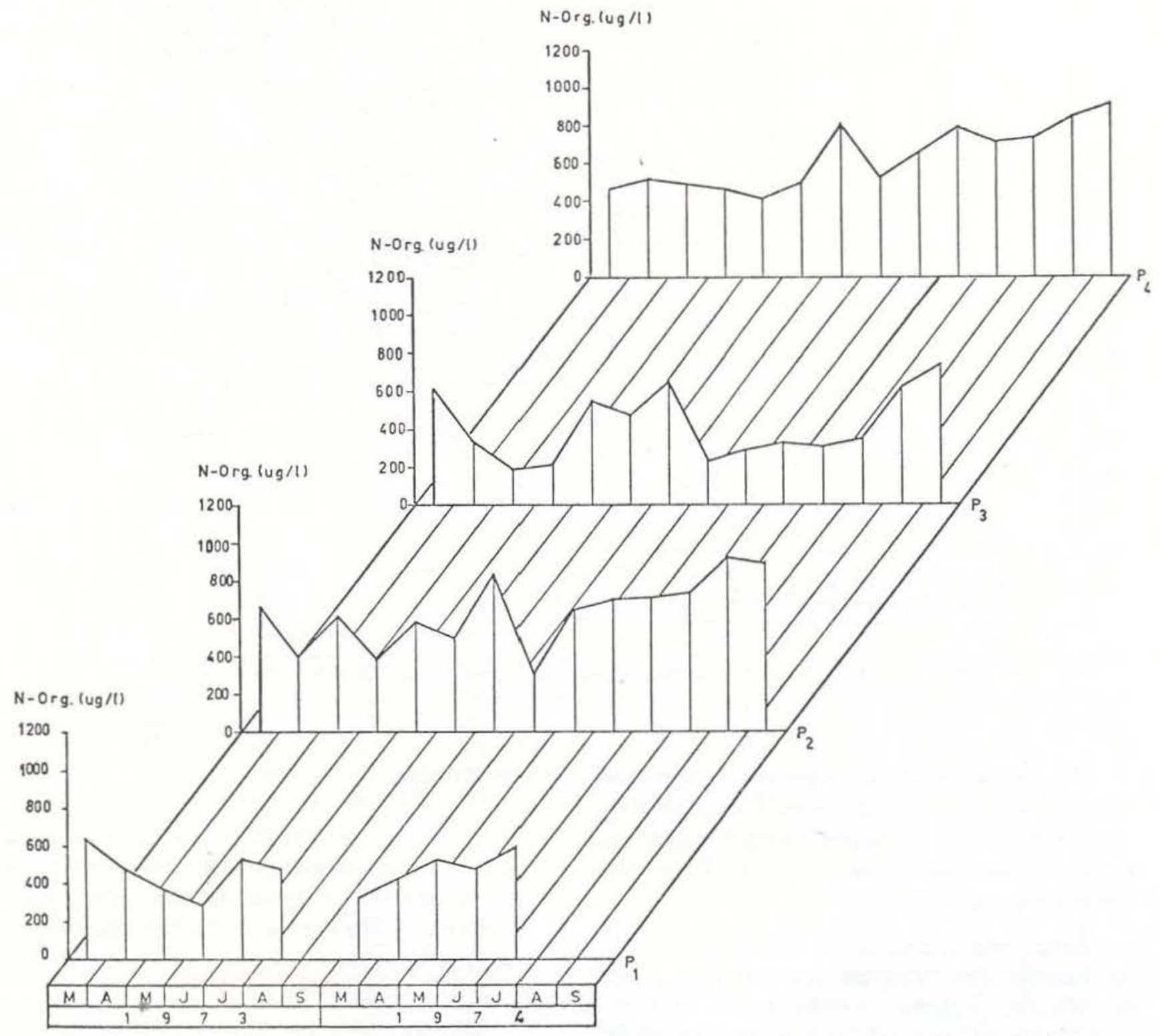

Fig. 6 - Variações mensais de Nitrogênio orgânico. 


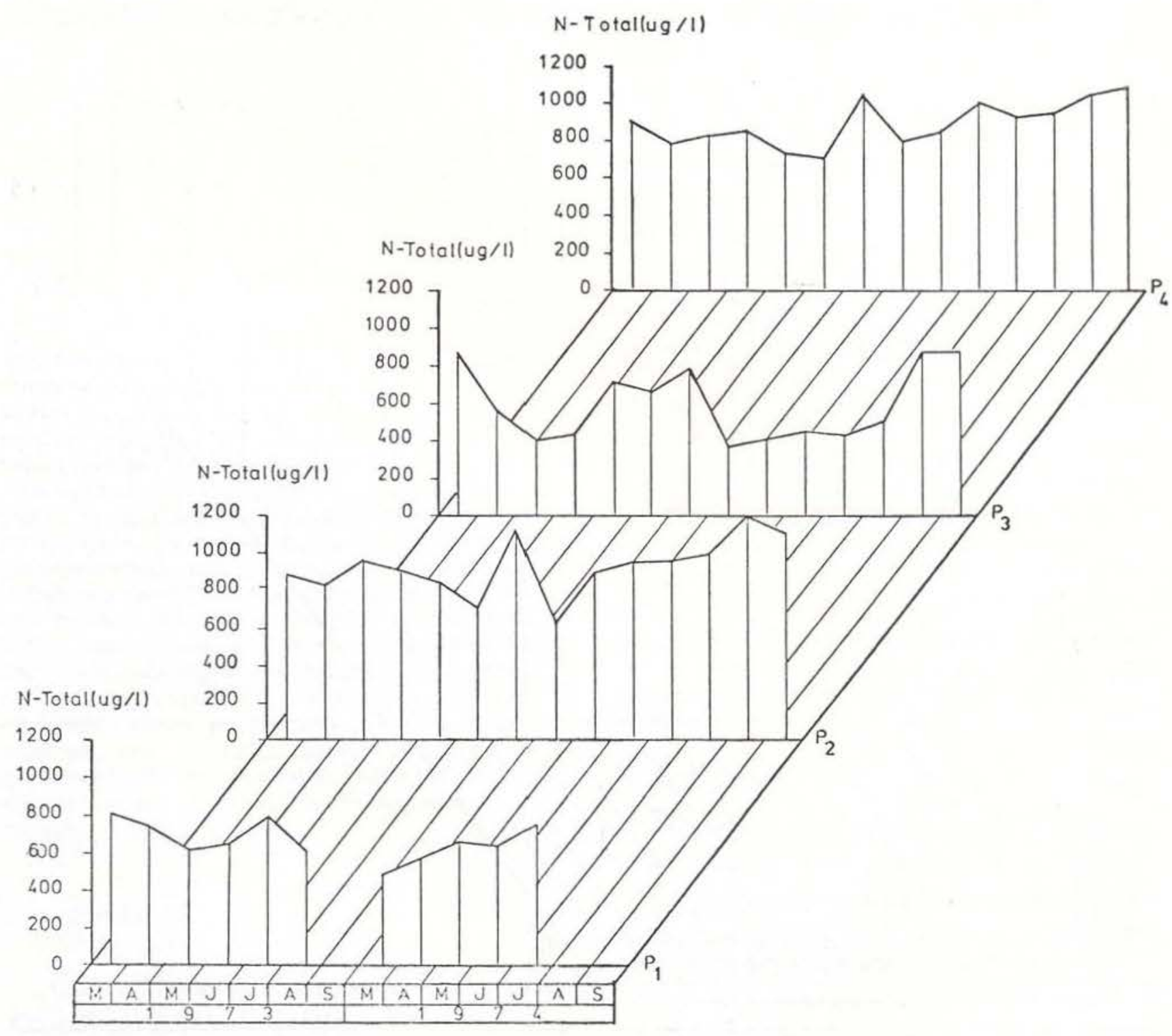

Fig. 7 - Variações mensais de Nitrogênio total.

\section{Agradecimentos}

Expressamos aqui nossos agradecimentos ao Dr. Herbert O. R. Schubart pelas sugestões apresentadas na apreciação do manuscrito, e a Sra. Anne Prance pela versão inglesa do sumário.

\section{SUMMARY}

The main source of nitrogen in the water of the soil of the eco-system of the Amazon Campina are the decomposing material, (litter), rain, water running of the vegetation and the biproducts of the metabolism of micro-organisms. Water samples taken from water table from four white sand sites (regosol) were analized for the components of nitrogen (Ammonia, nitrites, nitrates) and the concentration of the organic nitrogen and the total nitrogen were calculated. There was a greater concentration of nitrogen of an organic origin present than that from other origins. Ammoniac nitrogen was the principal product of the formation of organic material by micro-organisms and it had the second largest concentration, while nitrates and nitrites were almost always absent because of the acidity of soil $(\mathrm{pH} 3,0)$. There are annual and seazonal variations in the nitrogen compounds. The highest quantities are obtained in the middle of 


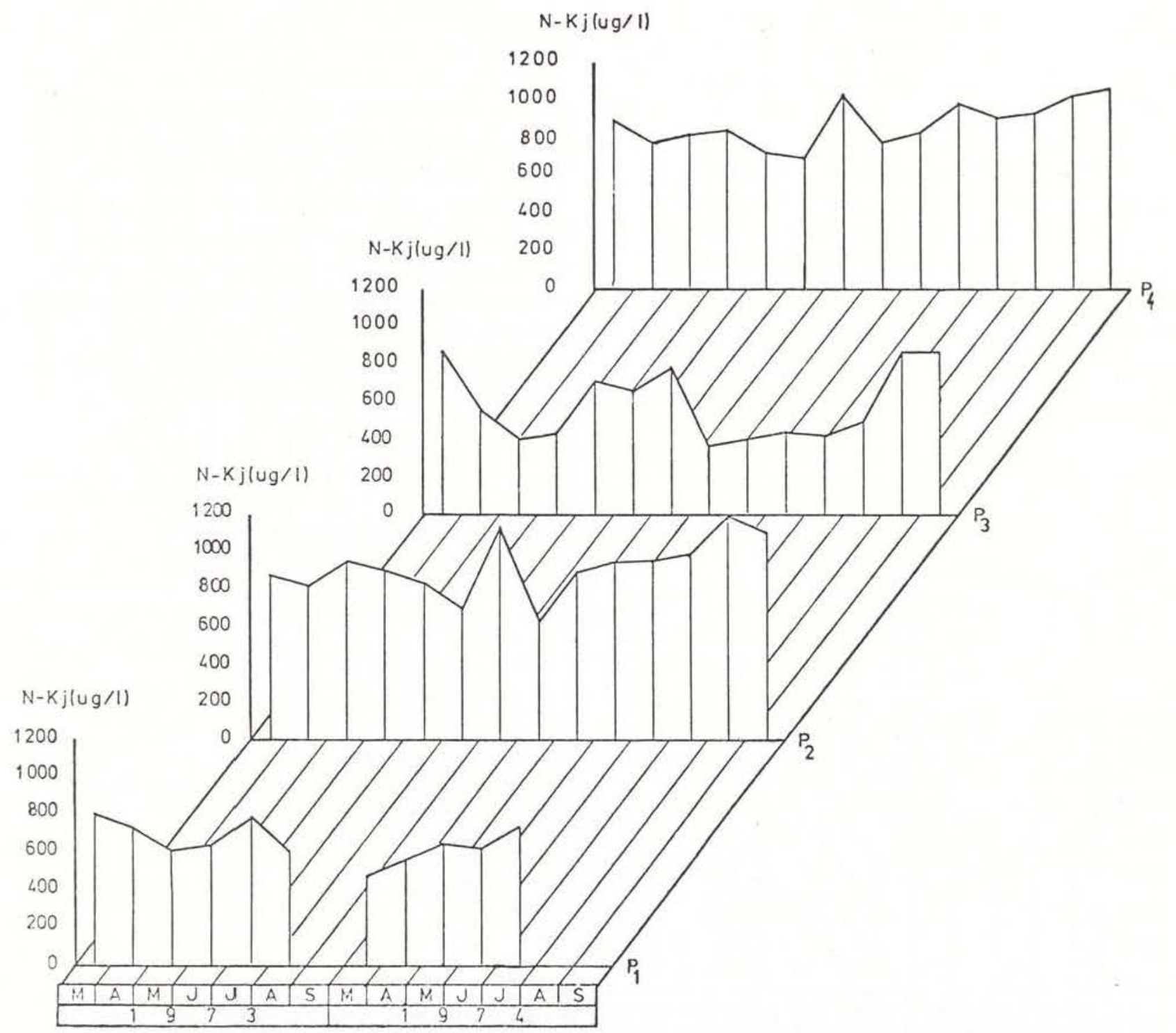

Fig. 8 - Variações mensais de Nitrogênio de Kjeldhal.

dry season owing immobilization of water table. In the natural conditions on white sand nitrogen is not a limiting factor for the development of the natural vegetation.

\section{BIBLIOGRAFIA CITADA}

ANON.

1972a - Regenwasseranalysen aus Zentralamazonien, ausgeführt in Manaus, Amazonas, Brasilien, von Dr. Harald Ungemach. Amazoniana, Kiel, 3(2): 186-198.

$1972 b$ - Die Ionenfracht des Rio Negro, Staat Amazonas, Brasilien, Nach untersuchung von Dr. Harald Ungemach. Amazoniana, Kiel, 3(2): 175-185.
BRINKMANN, W.L.F. \& NASCIMENTO, J.C. DO

1973 - The effect slash and burn agriculture on plant nutrients in the Tertiary Region of Central Amazonia. Acta Amazonica, Manaus, 1(3): 55-61.

IPEAAOC

1971 - Solos do Distrito Agropecuário da Suframa. Série solos, Manaus, 1(1): 13-99.

KLINGE, H. \& RODRIGUES, W.A.

1968 - Litter Production in an Area Amazonian Terra Firme Forest Part I. Litter-fall. Organic Carbon and total Nitrogen contents. Amazoniana, Kiel, 1(4):287-302.

RIBEIRo, M.N.G. \& SANTOS, A. DOS

1975 - Observações climáticas no ecossistema Campina Amazônica. (no prelo). 